\title{
Guillermo Jullian. La paleta del arquitecto
}

Sebastián Bianchi Profesor, Universidad Andrés Bello Lorena Pérez Profesora, Universidad Andrés Bello

Los medios de representación son, muchas veces, los que hacen particular una forma de hacer arquitectura. En el caso de Guillermo Jullian sus técnicas y recursos se hacen específicos y permanentes en todo su trabajo, desde su llegada al taller de Le Corbusier hasta sus últimas obras y pinturas.
The means of representation are, many times, those that decide the particular form of making architecture. In the case of Guillermo Jullian his resources and techniques are made specific and permanent in all of his work, from his arrival at Le Corbusier's studio to his latest works and paintings.
LA PALETA DEL ARQUTTECTO: COLOR, TROZOS Y GRILLA / Al enfrentarse al archivo que contiene la obra y al proceso creativo de Guillermo Jullian de la Fuente ${ }^{1}$, resulta evidente el valor estético y la carga de contenidos presentes en cada pieza. Sin embargo, es necesario que cada una de éstas sea comprendida como parte de un total y no como fragmentos aislados; en ese sentido, cada uno de los proyectos debe ser situado en el contexto de una gran conversación, dentro de la cual constituyen excusas pertinentes para discutir problemas de arquitectura que atraviesan transversalmente su obra.

Estas preocupaciones arquitectónicas que orientan la obra de Jullian, sumadas a un fino desarrollo de múltiples estrategias de representación, posicionan el resultado final de su trabajo en un estado intersticial entre arte y arquitectura.

Como el artista, Jullian define una paleta de elementos a partir de los cuales crea sus obras y que consta de tres componentes relacionados entre sí: la trama, el color y las piezas (entendidas estas últimas como fragmentos de obras anteriores, propias o ajenas). Estos elementos, que podemos reconocer como constantes en el desarrollo de su metodología proyectual, le permiten mantener una conversación abierta con sus propias inquietudes e intereses.

El soporte físico de cada ejercicio tiene un valor previo, ya sea por formato o significación, que constituye el punto inicial de la conversación. Objetos cotidianos como una cuenta de agua o un sobre u otros soportes tradicionales reutilizados como planos copia del mismo proyecto, dibujos a mano alzada o planos de situación, son el campo de juego sobre el cual se conjugan los elementos de la paleta.

Conjugados en diferentes cantidades e intensidades, la trama, el color y las piezas dan origen a cuatro estrategias de representación donde se plasman relaciones espaciales y arquitectónicas: el dibujo, el grabado, el collage y la pintura. Estos métodos expresivos aparecen a lo largo de su proceso creativo, ya sea individualmente o superponiéndose entre sí.

50 años de trabajo produjeron más de 60 proyectos, 94 libretas de croquis, 35 agendas, 2.930 croquis y collages, 3.415 planos entre originales y copias, cerca de 30 pinturas. Como un coleccionista, Jullian atesora todo este trabajo, elevando cada fragmento a una categoría de pieza única, firmándola y numerándola, para así hacerla parte de una serie; y timbrándola para asignarle un valor de pieza acabada.

EL CoLOR / Para Guillermo Jullian existían dos problemáticas asociadas al color. Una referida al origen cromático del pantone ${ }^{2}$ y otra al posible uso de éste sobre el proyecto.

En cuanto al pantone, Jullian manejaba una gama cromática que fue recolectada a lo largo de su vida. Su interés por el problema del color se gatilla en su paso por el atelier de Le Corbusier, donde incorpora los 16 colores básicos que allí se usaban; más tarde, producto de una insistente mirada a Piet Mondrian y de las conversaciones con su amigo Robert Slutzky ${ }^{3}$, aparece en su obra el uso de colores puros. Por último, se suman a este pantone los colores obtenidos de los lugares visitados en sus viajes ${ }^{4}$, donde reconoce tanto el color de las cosas como el color de la luz.

Esta serie de colores acompañaron a Jullian físicamente, en forma de pequeños trozos recortables, que servían de medida a sus proyectos. Así, se puede observar cómo este pantone de colores aparece con diferentes intensidades sobre el croquis, el plano y el collage tomando la forma de pasta, textura, lápiz o recorte.

Respecto a la significación dada al color, éste puede aparecer tanto como línea, asociada a un problema de límite espacial o elemento constructivo, o bien como problema de superficies, relativo a una noción de uso programático. De esta manera, el color adquiere una función de código, mediante el cual Jullian cualifica tanto la vocación del espacio como la naturaleza constructiva de las partes. En línea por ejemplo, el rojo representa la estructura opaca y el celeste la estructura transparente; en superficie, el amarillo es la circulación común, el naranja las estancias abiertas, el azul los espacios íntimos y el verde el jardín. Guillermo usa el color no para entender el vacío sino la construcción de la obra.

Los trozos / Los trozos son parte fundamental de la paleta de Guillermo Jullian, funcionando, a la vez, como declaración de principios y método proyectual. Surgen a partir de una acumulación de fragmentos de proyectos propios o ajenos, de los cuales se recogen relaciones de orden, tensión y espacio. De este modo se construye una especie de maleta de piezas y relaciones, de las cuales el arquitecto se apropia trasladándolas de un proyecto a otro. Esta lógica de traslado de ideas casi en un modo fisico se impregna en Guillermo en el atelier de Le Corbusier.

"El atelier era una especie de caja de Pandora donde estaban todas las ideas de Le Corbusier, sus libros, sus viajes, sus obras, todo lo cual usábamos como base para trabajar nuevos proyectos. Todas las cosas que utilizábamos para trabajar estaban ahí, desde antes, nosotros jugábamos con ellas (...) Siempre era posible volver al punto de inicio y dar pasos distintos, volver y avanzar, como un juego". ${ }^{5}$

Esta lógica de reutilización de piezas y partes crea una paleta acumulativa y temporal a la vez, donde las ideas que están en discusión acerca de un proyecto en particular, son parte de una conversación más amplia que es transversal a varios proyectos. La paleta de trozos recoge ese elemento transversal y otorga continuidad a las obsesiones y a las ideas.

LA GRILA / La trama o grilla es una estructura de orden físico sobre la cual se vinculan piezas y relaciones; es otro elemento del pantone que aparece, en forma evidente o implícita, a lo largo de prácticamente todo el proceso de creación.

Guillermo realiza numerosas estrategias de exploración ${ }^{6}$ acerca de las posibilidades de configuración, orden y grados de libertad de la grilla, en cuanto a las diversas maneras de utilizarla como estructura flexible, de negarla e incluso hacerla desaparecer. Esta búsqueda guarda relación con una necesidad de comprender la trama no sólo como una disposición de orden abstracto, sino como una estructura espacial compleja. Sobre esta grilla, se ordenan y relacionan color y fragmentos. 
' Todas las imágenes que se muestran en este artículo han sido reproducidas por los autores y fueron donadas por Guillermo Jullian al Archivo de Originales del Centro de Información y Documentación Sergio Larraín García Moreno de la Facultad de Arquitectura, Diseño y Estudios Urbanos
${ }^{2} \mathrm{Al}$ igual que Le Corbusier, Jullian de colores como herra

proyecto y re pantone personal (N. del Ed.).
${ }^{3}$ Robert Slutzky (1929-2005) fue pintor, escritor y educador, coautor del libro Transparencia literaly

fenomenal con Colin Rowe. En un influyente ensayo analiza la relación entre arquitectura y arte moderno; su vida fue una larga exploración acerca de las conexiones entre

pintura y arquitectura, influenciando en esta búsqueda a gran parte de
${ }^{4}$ El viaje para Jullian era un modo de materia para volcar en sus proyectos.

Ver entrevista de Claudio Vásquez "Conversación con Guillermo Jullian de la Fuente". En: Massilia 2007, una generación de arquitectos.

6 YPD (Yellow Pheripherical Disctinction). Este estudio hace referencia al concepto de in-between o espacio intermedio introducido por Aldo Van Eyck y consiste la comprensión de las lineas de la grilla como espesor, programático y habitable.

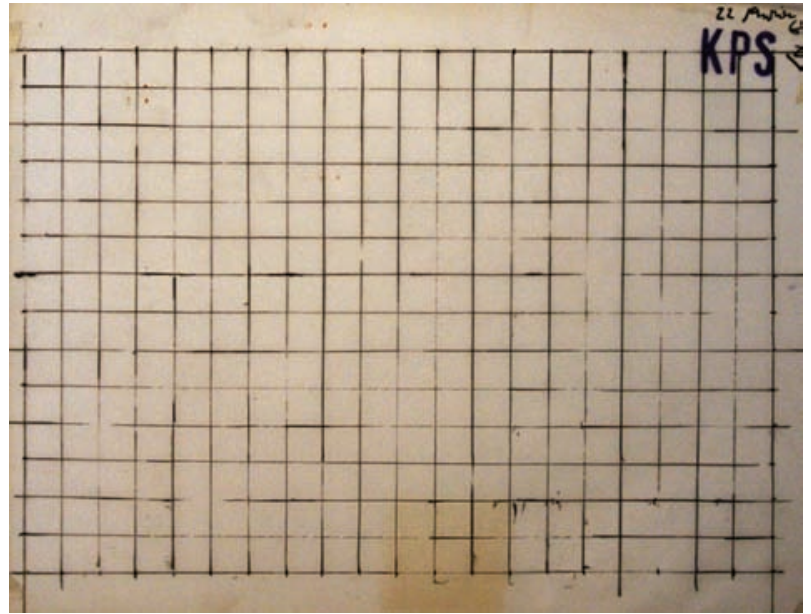
01

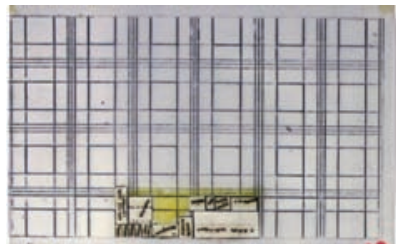

$\frac{a}{a x}$
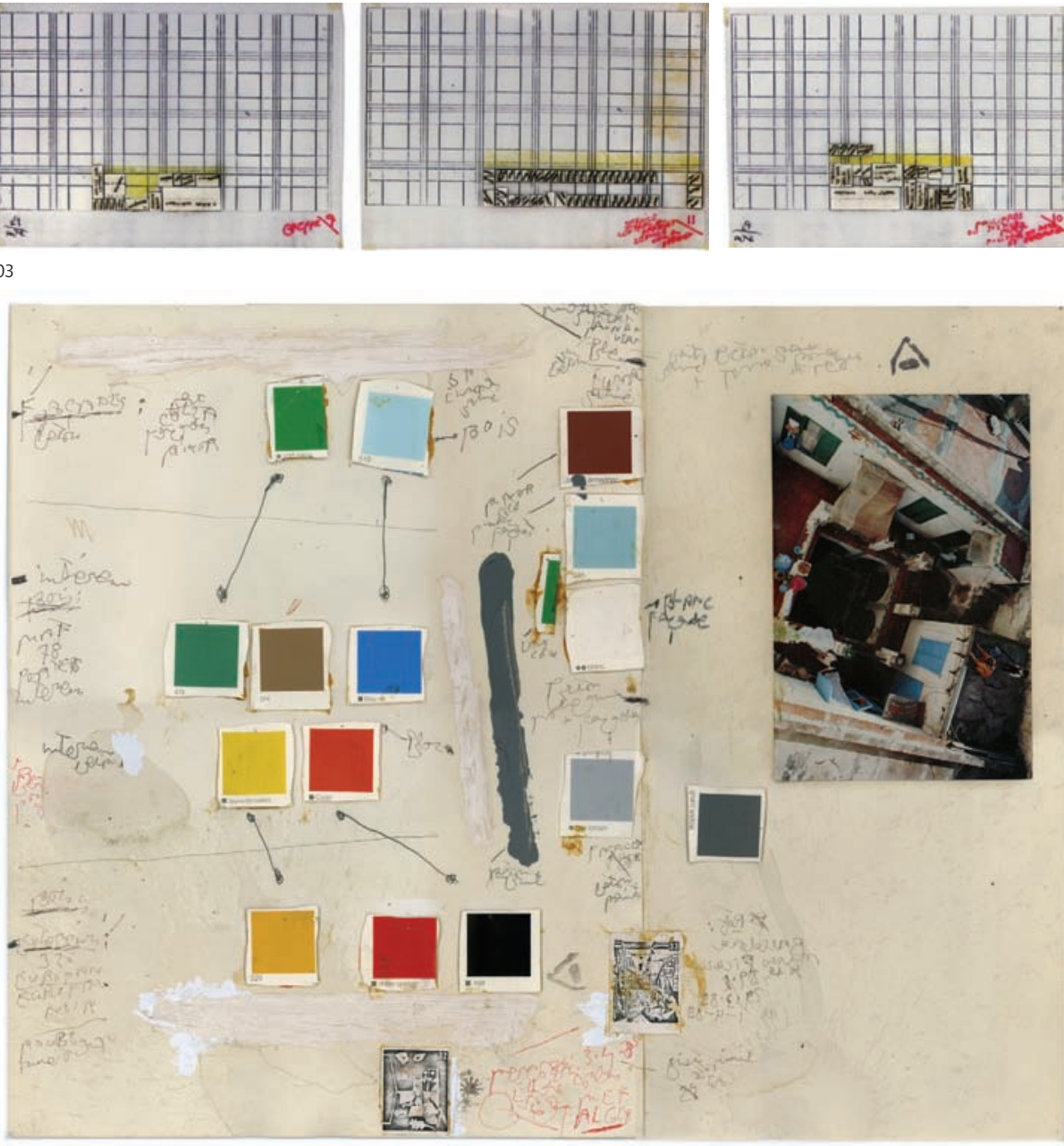

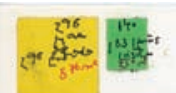

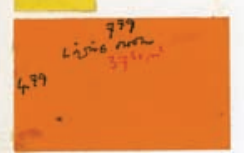

$3^{66} \operatorname{com}_{19}^{499}$ andistan

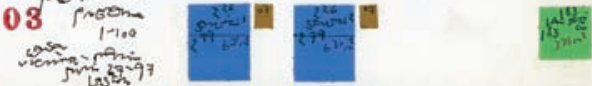

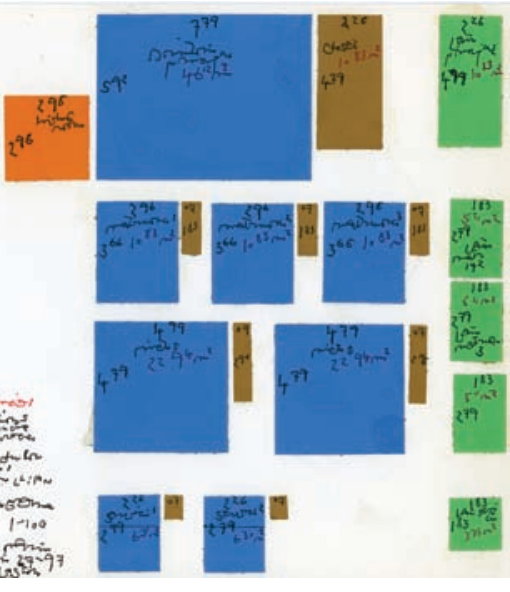

S4s chisition
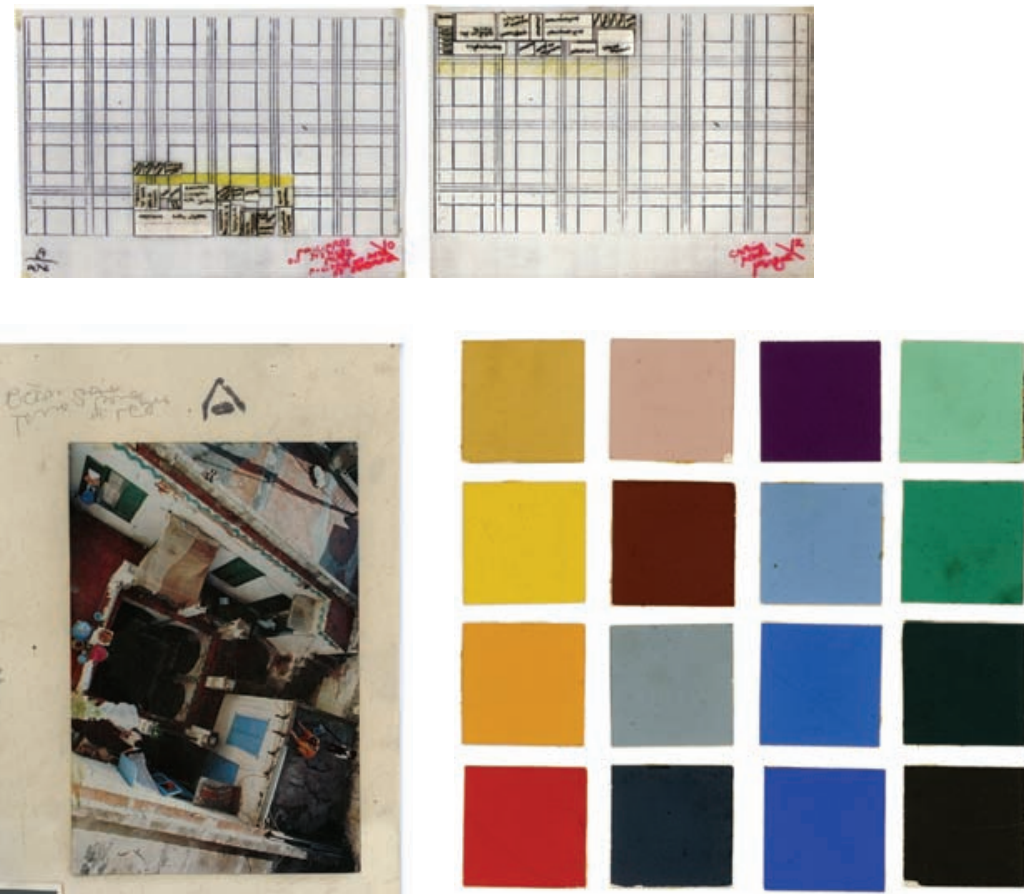

05

01Casas móviles Koopers, 1969

Grilla de base en tinta negra sobre papel diamante

02 Casa Vicuña en Zapallar, 1997

Trozos de papel definen programa y metraje cuadrado del proyecto. 03 Corte de Justicia de Lyon, 1981

Collage de trozos de programa sobre grilla a tinta en papel diamante

04 Embajada de Argelia, Bureaux, 1985

Pantone para ser usado en el proyecto, desarrollado en base a una fotografía del lugar 05 Pantone de 16 colores usados en el atelier Le Corbusier, 1951 

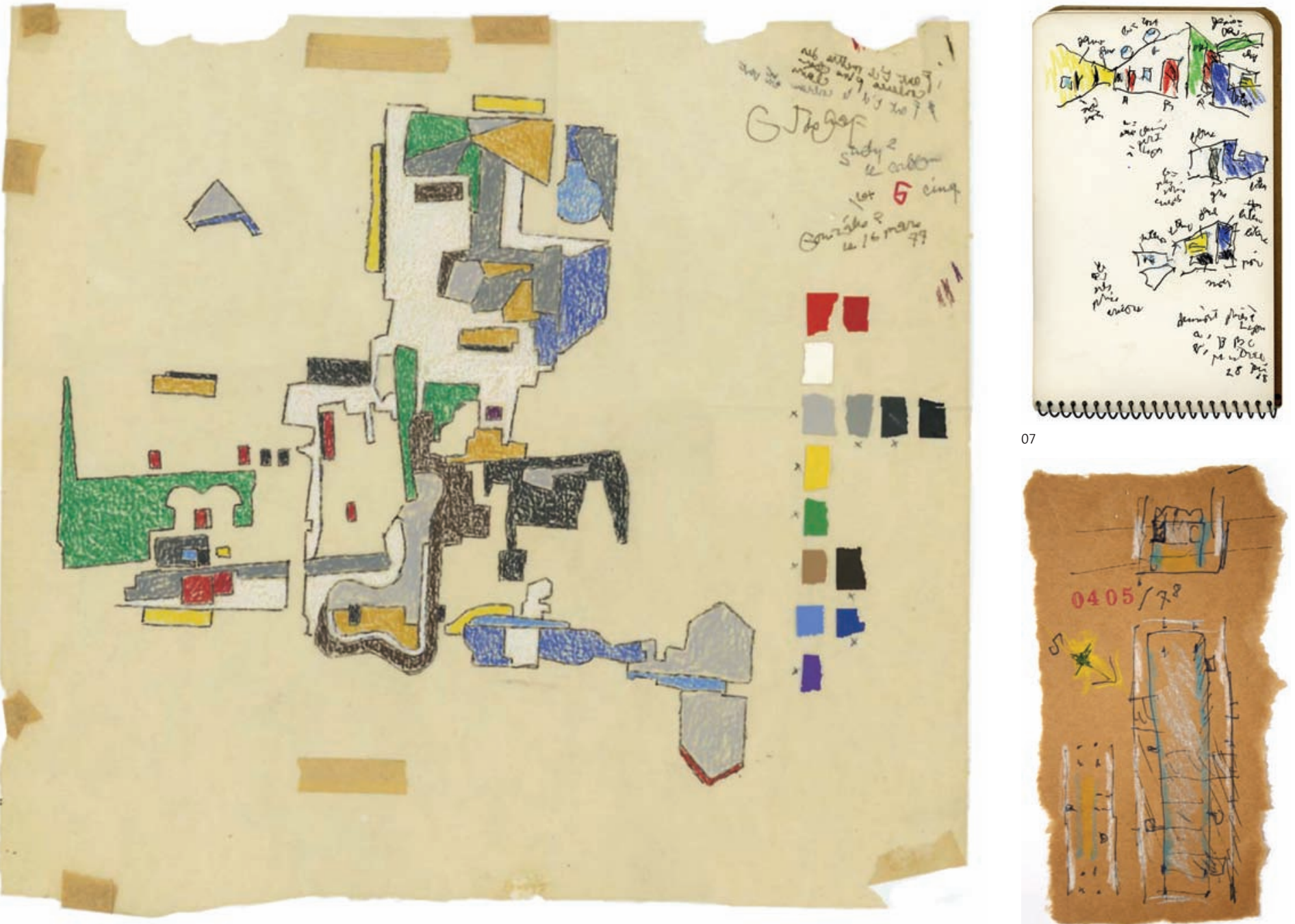

06

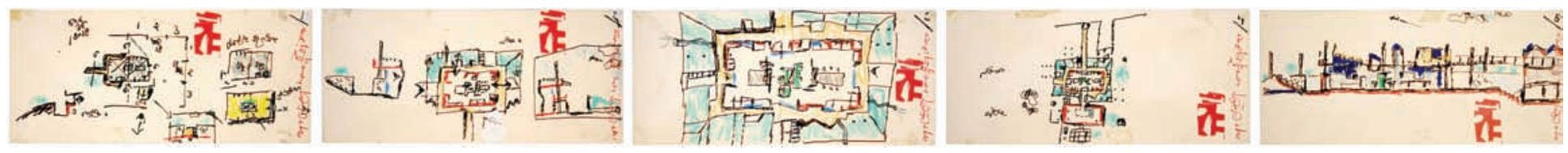

TÉCNICAS - EL DIBUJO, LA MIRADA ABIERTA DE LAS COSAS / Esta estrategia de representación denota una voluntad por mantener una mirada abierta sobre los problemas discutidos sobre el papel. El dibujo se construye a mano alzada, de trazo intenso y forma aparentemente imprecisa, pero rigurosa en sus relaciones.

Existe en Guillermo Jullian una desconfianza por la perfección en el dibujo en la medida en que ésta impide la continuidad, en tanto cierra la conversación y vuelve inerte el papel. En su dibujo, más visceral y más intuitivo, aparece una vía de escape.

El dibujo es también una forma de apropiación. Jullian continuamente re-dibuja, no sólo sus proyectos -sobre papel diamante a lápiz, a modo de calco-, sino también proyectos de otro, como un modo de apropiarse de lo ajeno e interiorizarlo.

Finalmente, el dibujo se traslada de herramienta de proyecto a mecanismo de intervención y redefinición de la obra concluida. 


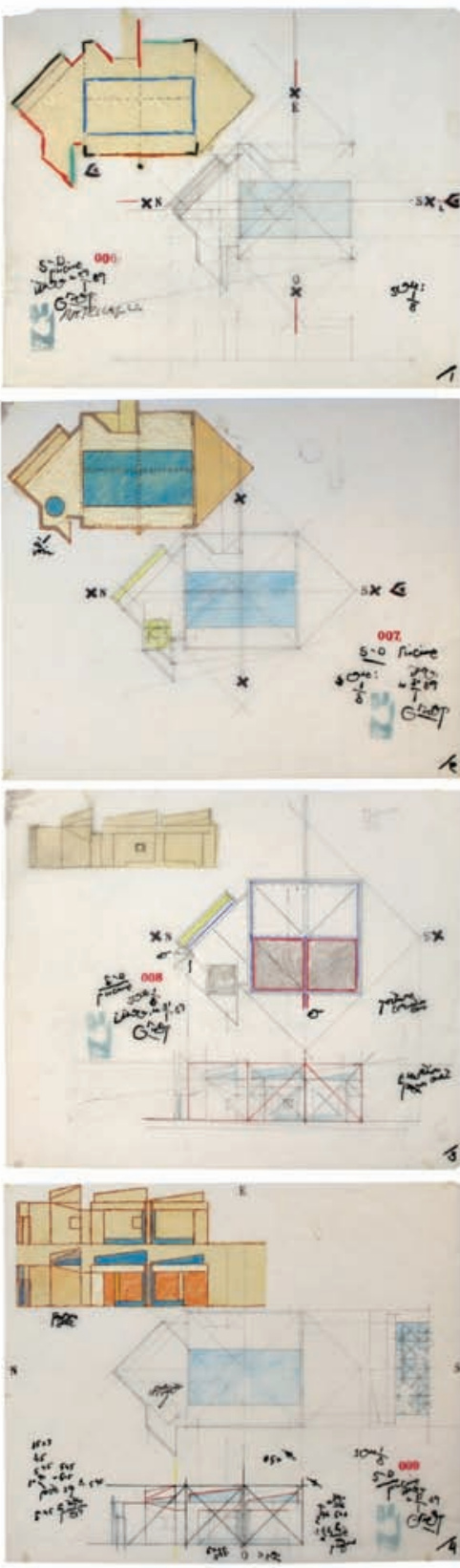

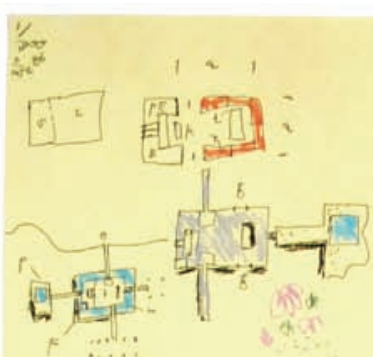

$\sum_{\infty}^{2}$
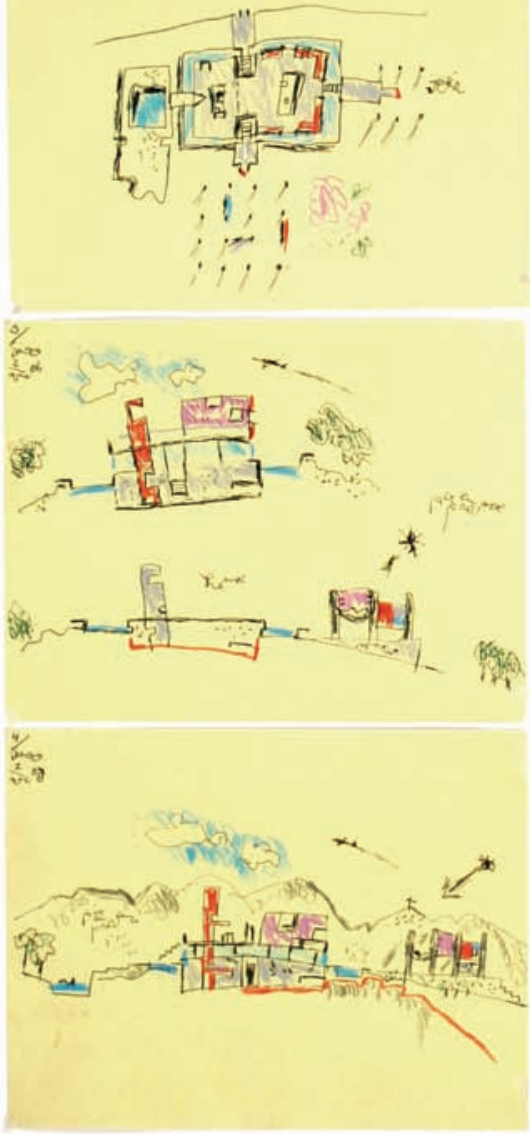
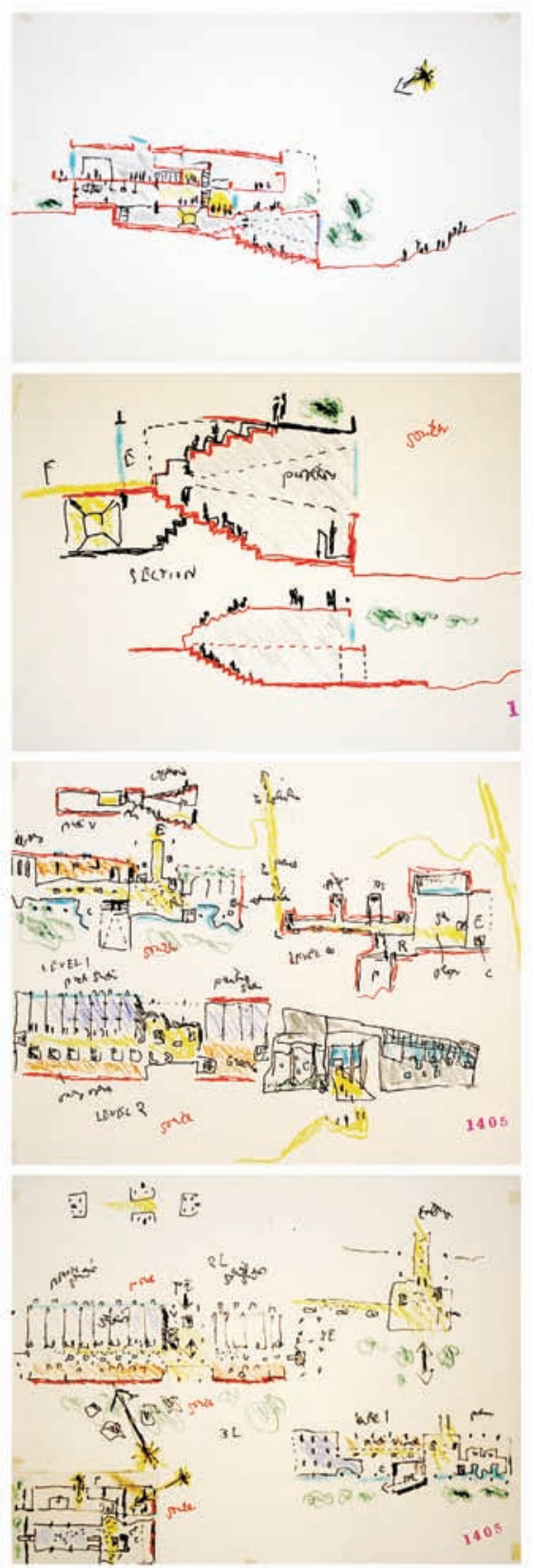

06 Plaza Gonzales, EE.UU., 1977

Dibujo con lápices de colores sobre papel y collage de trozos de papel pintado con acrílico pegados sobre el dibujo

07 Ático de la BBC, Lyon, 1968

Dibujo a lápiz de color en croquera pequeña

08 Stoll Field, Campus de la Universidad de Kentucky, EE.UU., 1978

Dibujo a lápiz de color y tinta negra sobre papel kraft

09 Tres casas en Ithaca, 1987

Dibujo a lápiz de color en sobres de papel tamaño oficio. Serie completa timbrada con ícono del proyecto en tinta

roja y numerada del 1 al 5

10 Piscina casa Sagan, Ithaca, 1989

Dibujo a lápiz de color sobre papel diamante, usado como calco

11 Tres casas en Ithaca, 1987

Dibujo a lápiz de color sobre hojas carta color amarillo. Serie compuesta por cuatro piezas numeradas

12 Stoll Field, Campus de la Universidad de Kentucky, EE.UU., 1978 


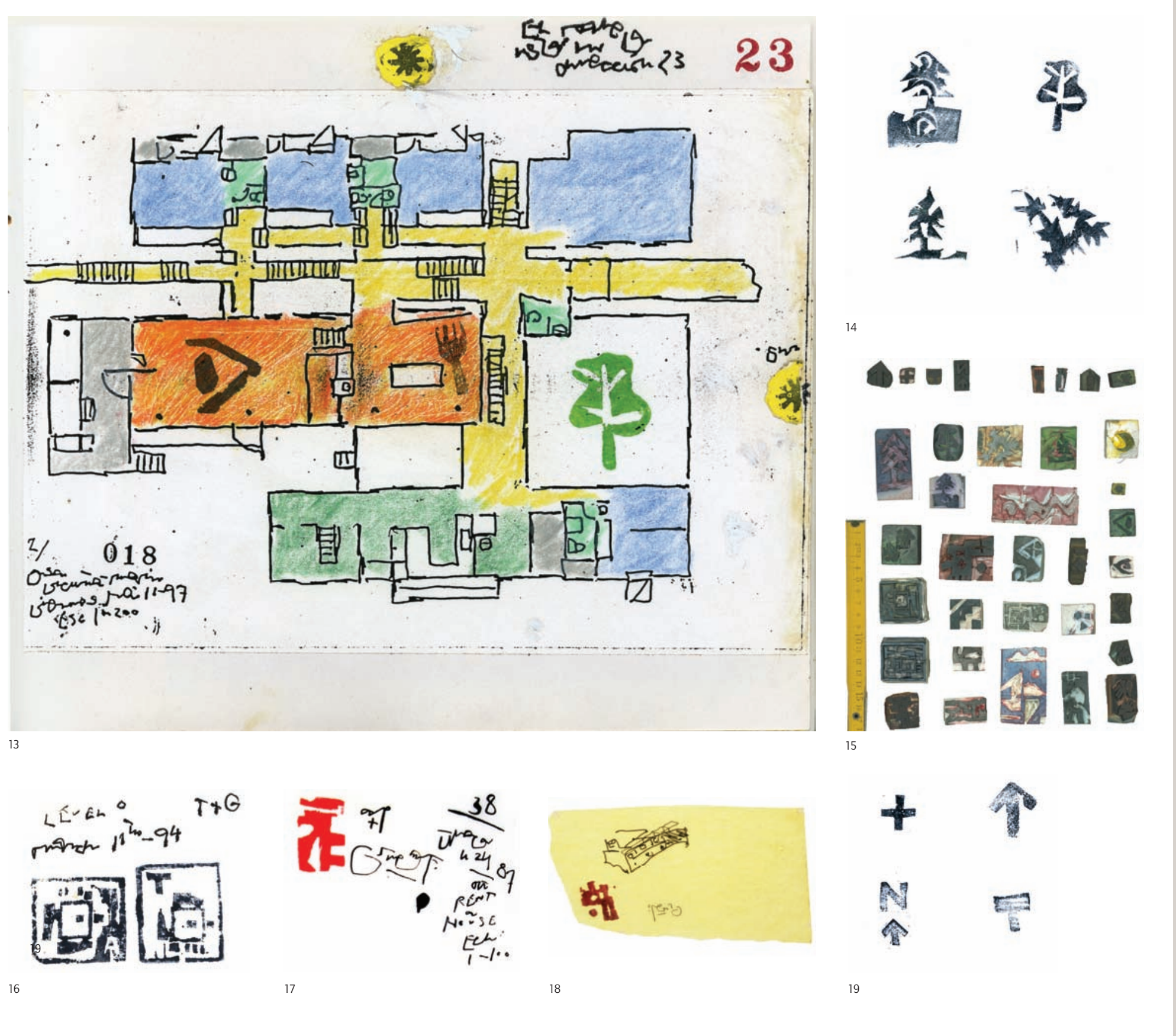

TÉCNICAS - EL TIMBRE, MEMBRETE Y SÍMBOLO / Si bien el timbre aparece como técnica en el proceso creativo de Guillermo Jullian durante su estadía en el atelier de Le Corbusier, su uso se extiende a lo largo de toda su obra.

Pequeñas piezas talladas en goma de borrar, cuidadosamente elaboradas, se van acumulando con cada nuevo proyecto desarrollado. Guillermo guardaba estas piezas, algunas heredadas de Le Corbusier y otras generadas en su atelier, como un nuevo pantone compuesto por tres tipos de timbres: símbolos, marcas instructivas sobre el papel e iconografías de proyectos.

Los primeros corresponden a aquellos que se colocan sobre el dibujo o collage en relación con el resto de los elementos. Un ejemplo de estos es el hombre nuevo, heredado del atelier Le Corbusier, que aparece como una unidad de medida sobre el dibujo, para escalar y fijar proporciones y relaciones. Otros timbres como el sol, el ojo, la oreja, la botella o el tenedor no tienen escala, pero permiten intensificar la capacidad del dibujo y collage para evocar cualidades programáticas relacionadas al lugar de comer o estar; otras veces relacionadas al ambiente, como el sonido, la vista, la luz. En cierta forma, es un intento de Jullian por introducirse de un modo más vivencial en la obra.

En segundo lugar, aparece el timbre como señalador o marca instructiva, que es utilizado casi exclusivamente sobre la planimetría, con un fin indicativo para orientar discusiones acerca de modificaciones y avances en el proyecto.

Finalmente, los timbres asociados a iconografias de proyecto son por un lado declaraciones de principios en cuanto a lo que el proyecto pretende ser y, por otro, generadoras de un imaginario en torno a las temáticas del mismo. De cierto modo, estos timbres sintetizan el proyecto $y$, a modo de viñeta, sellan la pieza gráfica y la codifican, otorgándole valor como parte de una serie mayor, además de validar cada pieza con el peso de un original. 

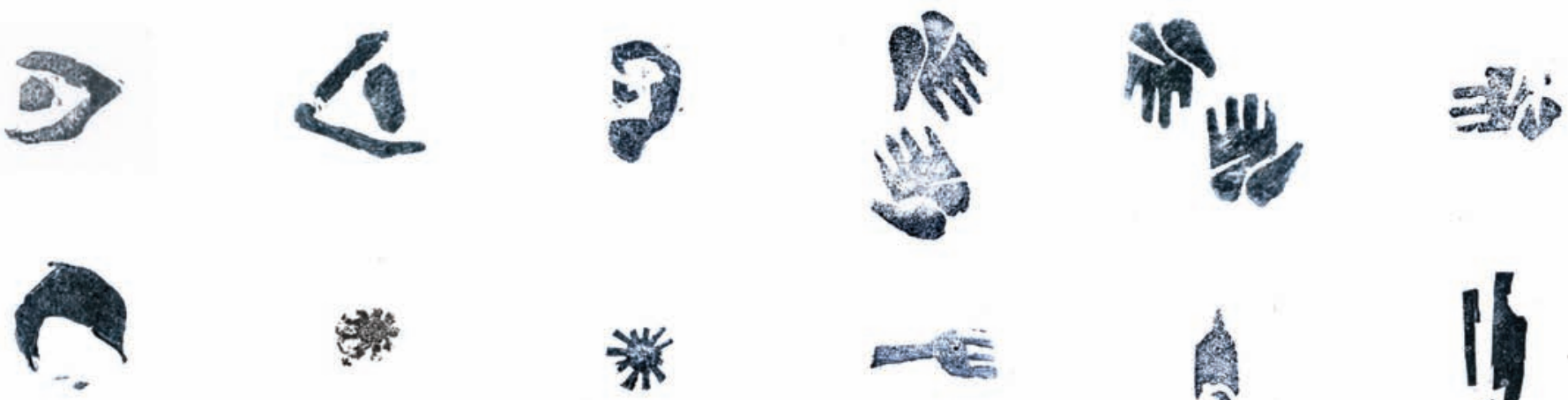

骤

漴

enesise
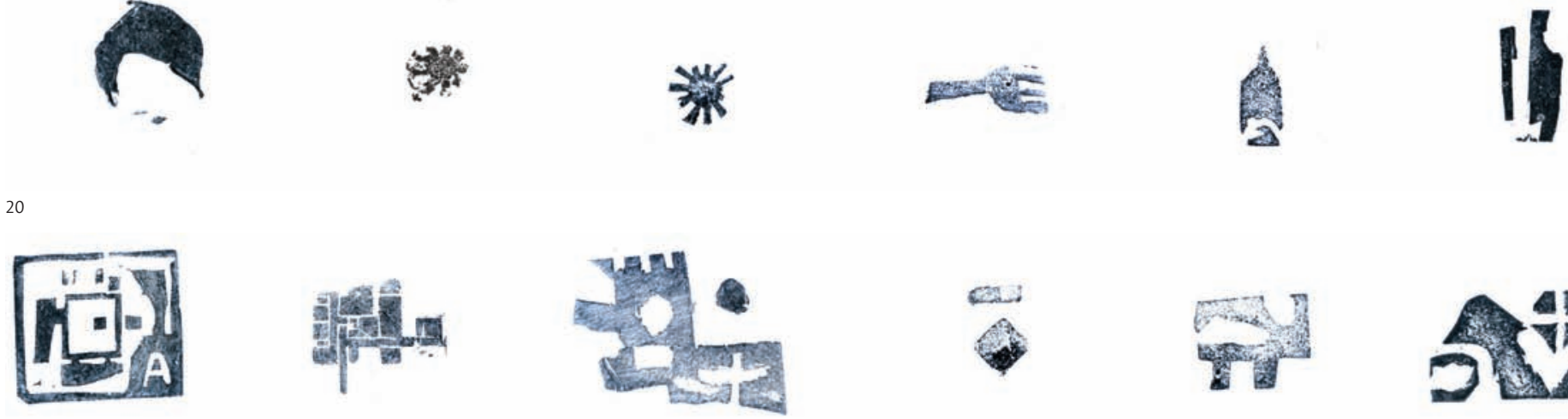

as
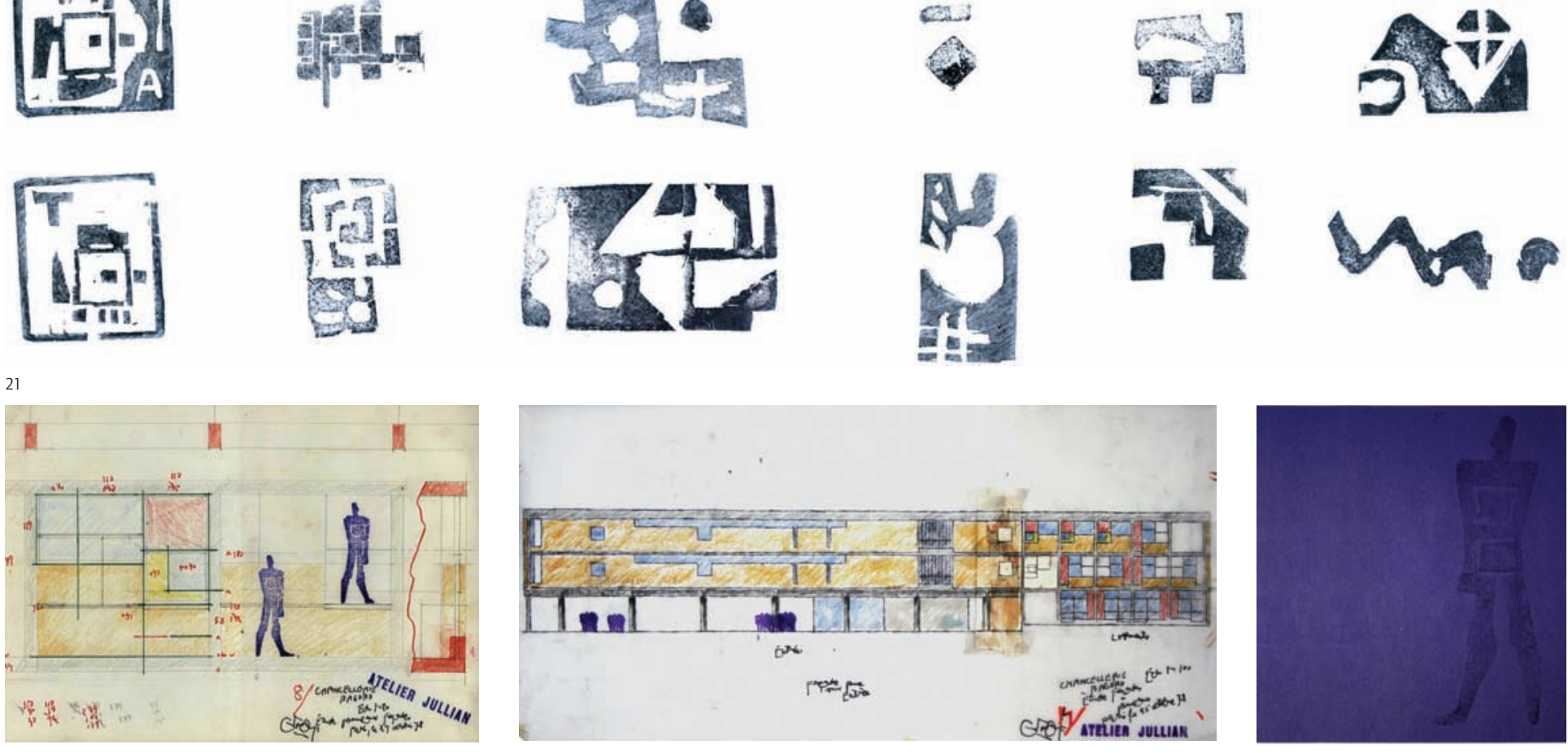

13 Casa Vicuña, Zapallar, Chile, 1997

14 Serie de impresiones de timbres relacionados a masas y objetos vegetales, escalados entre sí

Planta de proyecto con timbres del ojo, el tenedor, el sol y el árbol

15 Serie de timbres tallados en goma de borrar, escalados entre si

16 Iglesia de Roma, 1978

Timbre y firma que componen la viñeta del proyecto

17 Tres casas en Ithaca, 1987

Timbre y firma que componen la viñeta del proyecto

18 Piscina casa Sagan, 1987

Timbre de proyecto

19 Timbres de marcas instructivas

20 Serie de impresiones de timbres relacionados a problemas de uso de los recintos y cualidades lumínicas

21 Serie de timbres íconos de proyectos

22Cancillería de Bagdad, 1978

Timbres del modulor, sobre sección del proyecto, escala 1: 10

23 Cancillería de Bagdad, 1978

Timbre del modulor en conjunto de personas, sobre fachada de proyecto

24 Timbre del modulor sobre papel azul, 1978. Escala 1: 10 

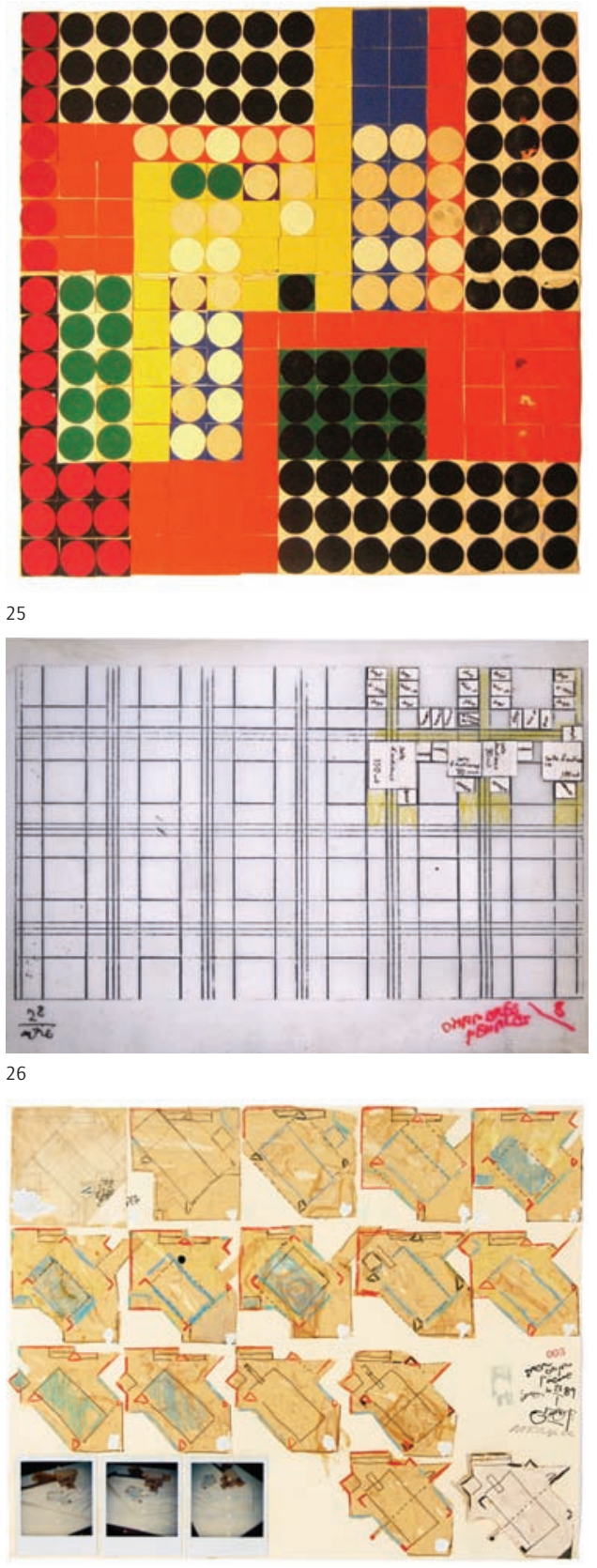
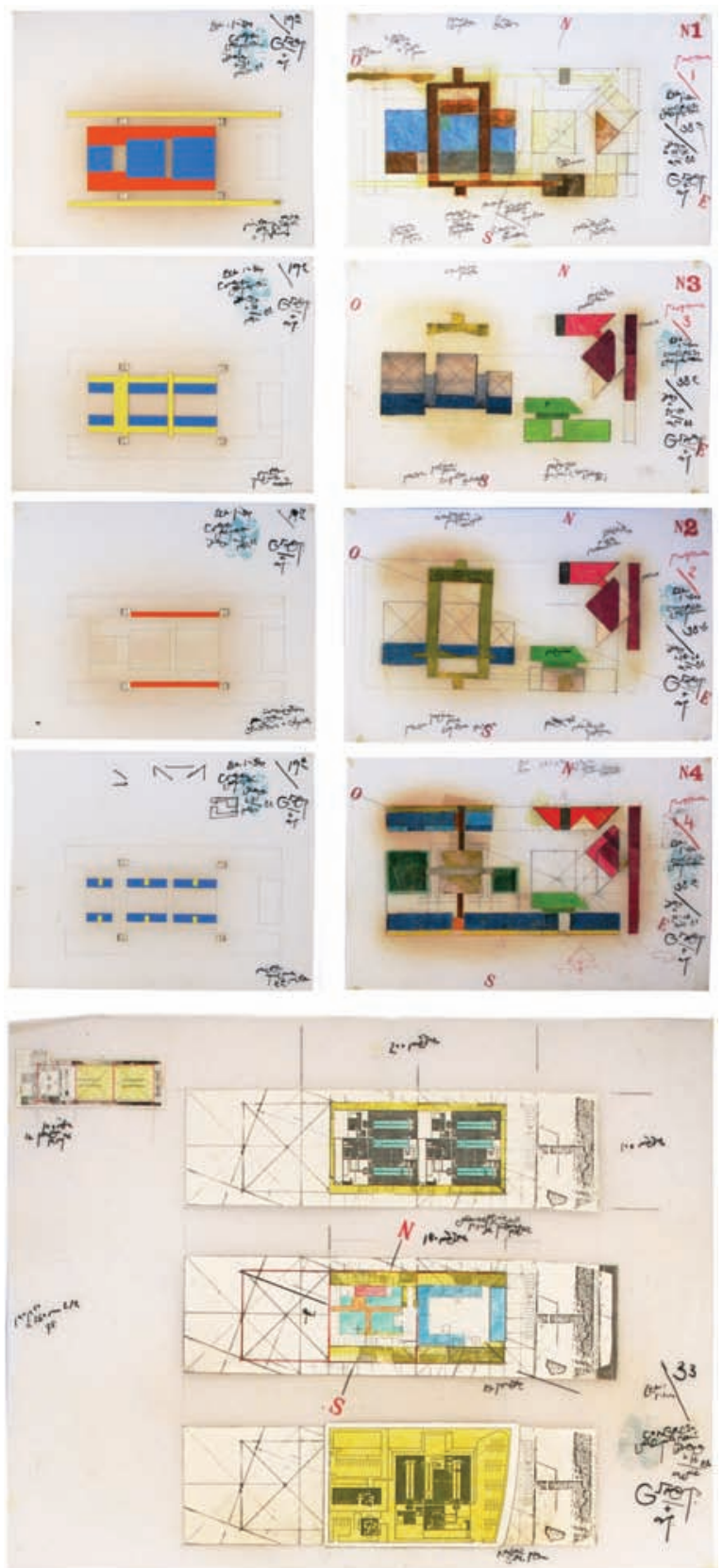
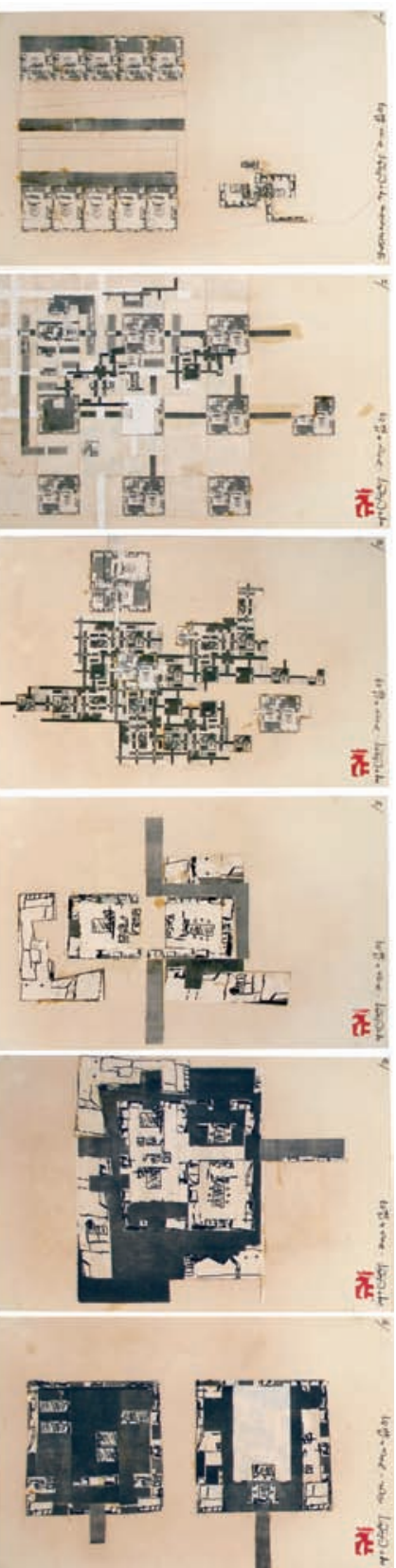

TÉCNICAS - El COLLAGE, CAPAS DE PROBLEMAS / Para Jullian el collage es un modo de entender el mundo que, dada su libertad de superponer infinitas capas de problemas, permite generar un soporte abierto a la conversación.

Tal como enseñaba, Jullian entendía el proyecto como un continuo proceso, donde, al tiempo que se avanzan dos pasos se retrocede uno y en el cual la estrategia del step by step ${ }^{7}$ sugiere un caminar donde el paso siguiente podría modificar o destruir al anterior. Mediante el uso de esta técnica, existe la voluntad por evidenciar el traslado de ideas de un proyecto a otro, la arquitectura no parte de cero, sino que es un proceso donde las partes se arman, desarman, transforman y relacionan de nuevas maneras.

El collage es una técnica mediante la cual se piensa, un proceso que en su construcción requiere de una continua selección, tanto del fondo como de las piezas que se colocan sobre éste. Primero, se escoge un material como punto de partida, que normalmente se fotocopia, recorta y se pone sobre un fondo. Sobre este producto inicial, pueden superponerse otros elementos, colores o trozos, apareciendo sucesivas capas de material que son capas de problemas, donde la adicción y sustracción son parte de la reflexión. Esta secuencia puede ser indefinida, salvo que aparezca la firma, donde el problema puntual queda cerrado, convirtiéndose en material para otra conversación. ARQ

\section{Bibliografía sugerida}

Alonso, Pedro y Rodrigo Pérez de Arce. "La capilla del hospital de Venecia”. En ARQ № 47, La intuición. Ediciones ARQ, Santiago, abril de 2001./ Jullian, Guillermo. “Casa Sagan, Ithaca, Nueva York”. En ARQ № 21. Ediciones ARQ, Santiago, septiembre de 1992. / Jullian, Guillermo. "Casa Loubejac”. En ARQ № 29. Ediciones ARQ Santiago, abril de 1995. / Pérez de Arce, Rodrigo. Guillermo Jullian, Obra abierta. Ediciones ARQ Santiago, 2000. / Petrelli, Amedeo. "Un hospital es una 'Casa del Hombre'. El hospital de Venecia de Le Corbusier”. En ARQ № 46, El habitante. Ediciones ARQ Santiago, octubre de 2000. / Vásquez, Claudio (ed). Massilia 2007. Guillermo Jullian de la Fuente. Ediciones ARQ, Santiago, 2008. 
7 Frase recurrente usada por

Guillermo Jullian en sus lecciones de

taller de arquitectura en la Pontificia

Universidad Católica de Chile.
25 Collage parte del estudio Yellow Pheripherical Distinction, realizado con círculos de papel de colores

26 Corte de Justicia en Lyon, 1987. Collage con trozos de copias, sobre grilla dibujada a tinta negra sobre pape diamante

27 Piscina casa Sagan, 1987. Series de collages sobre copias de planta del proyecto

28 Congreso de Valparaíso, 1987. Tres series de collage sobre copia del terreno de proyecto, composición realizada con trozos de cartulina, lápices de color y trozos de copias de anteproyecto

29 Tres casas en Ithaca, 1987. Serie de collages realizados con trozos de copia de planta del proyecto. Firmadas, timbradas y numeradas del 1 al 6

30 Tres casas en Ithaca, 1987. Dibujo, collage y pintura (trozos de papel y pintura acrílica sobre papel kraft). Pieza timbrada con ícono del proyecto en tinta roja en el costado izquierdo

31 Lámina del proyecto de la casa Vicuña, con fotografía Polaroid del taller de Guillermo Jullian en Estados Unidos e imágenes de pinturas en proceso

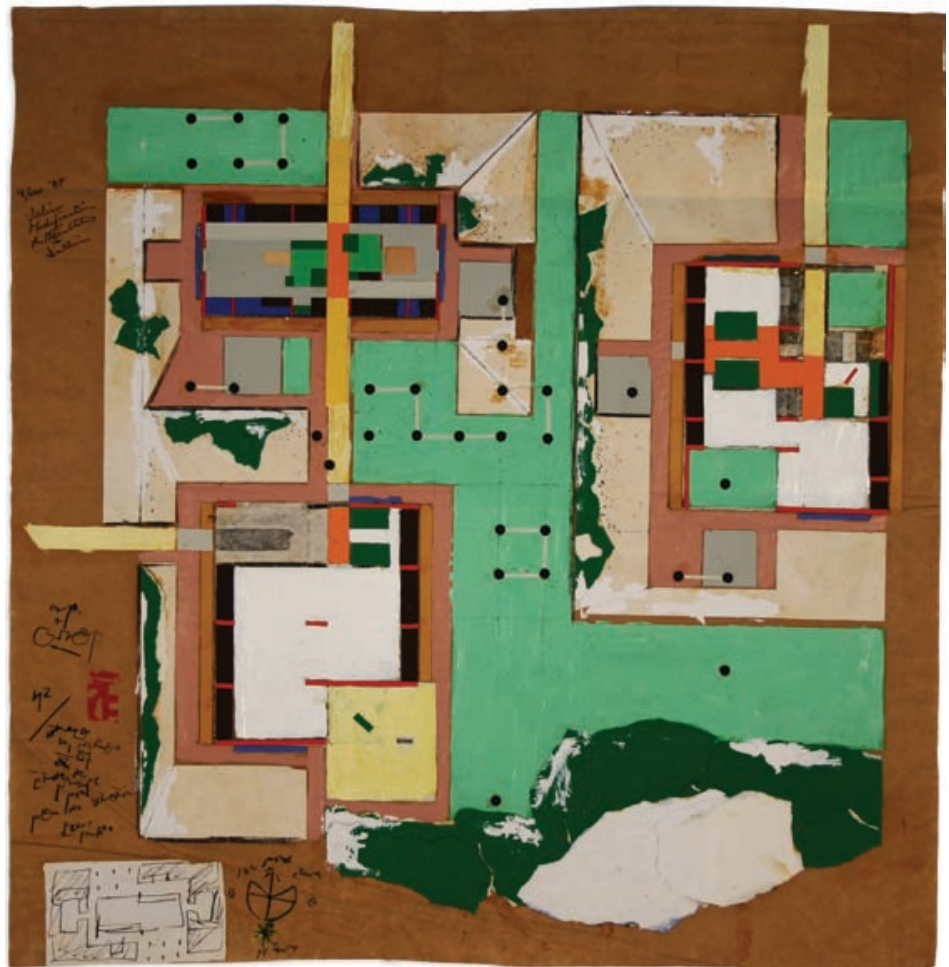

30
0

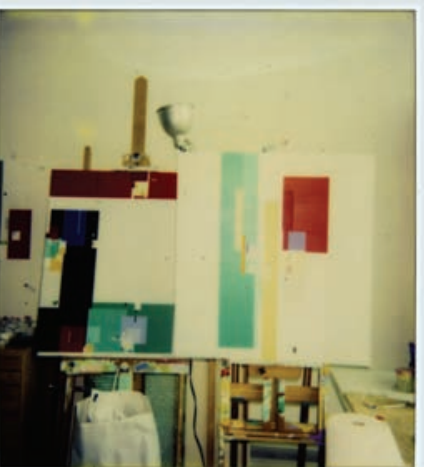

\section{BIOGRAFÍA}

La relevancia de Guillermo Jullian de la Fuente, quien murió a principios de 2008 a los 76 años de edad, radica en las relaciones entre su quehacer en torno a lo arquitectónico y los planteamientos del Movimiento Moderno. Luego de titularse en 1958 en la Escuela de Arquitectura de la Universidad Católica de Valparaíso, donde se aproxima por primera vez a los preceptos de una enseñanza moderna de la arquitectura que marcaría para siempre su carácter, Jullian viaja a Europa a formar parte del atelier de Le Corbusier.

Desde aquel año hasta la muerte de su maestro asumió como Jefe de Taller del atelier, siendo responsable de importantes proyectos. Desde 1973 participó en relevantes congresos de arquitectura moderna, como el cIAm de Berlín o la reunión del Team 10 en Lisboa en 1981. Esta participación en las discusiones de contingencia y las relaciones con otros distinguidos miembros del Movimiento Moderno fueron fundamentales para la formación de su carácter como arquitecto. Su paso por la Universidad Católica de Valparaíso, su cercanía a Le Corbusier, el contacto con arquitectos como Aldo Van Eyck, Sadrach Woods y Robert Slutzky en Estados Unidos fueron experiencias determinantes en la definición de una cierta manera de pensar, en el desarrollo de un método de trabajo basado en la intuición y en el juego y en el diseño de sus obras a través de la idea del collage.

Testigo activo de los principios del Movimiento Moderno que marcan el desarrollo de toda la arquitectura contemporánea, Guillermo Jullian desarrolla y construye proyectos en Europa, Estados Unidos, América Latina y África. Fue publicado en reconocidas revistas y participó activamente en distintas conferencias. Conjuntamente con mantenerse vigente en el campo profesional, Guillermo Jullian fue profesor en las universidades de Trondheim en Noruega, Rice, Texas, Harvard, Cambridge Mass, Cooper Union, N.Y. Kentucky, Cornell e Ithaca, en los Estados Unidos. En sus últimos años de vida fue profesor invitado de la Universidad de Pennsylvania en Filadelfia profesor honorario de la Universidad San Antonio Abad del Cuzco y profesor de las universidades Católica de Chile, Diego Portales y Andrés Bello en Santiago.

Su larga y fructífera trayectoria como arquitecto y educador le otorgaron reconocimiento internacional, habiendo dado al final de su carrera una conferencia acerca de su vida y obra en la Università Roma Tre en Italia. Pese a la innegable relevancia que su persona detenta en el exterior, en el panorama de la arquitectura nacional es reconocido sólo dentro de un círculo selecto que ha tenido la posibilidad de estudiar su obra.

La reciente donación de su archivo personal a la Pontificia Universidad Católica de Chile, conformado por todo el material que desarrolló a lo largo de su vida, presenta una oportunidad única para difundir su obra y su trayectoria en e ámbito chileno. 